\title{
Effects of a randomized controlled trial of a brief, student-nurse led, parent-based sexual health intervention on parental protective factors and HPV vaccination uptake
}

\author{
D. Santa Maria ${ }^{1 *}$ (D, C. Markham², S. M. Misra ${ }^{3}$, D. C. Coleman ${ }^{1}$, M. Lyons' ${ }^{1}$ C. Desormeaux ${ }^{4}$, S. Cron ${ }^{4}$ and \\ V. Guilamo-Ramos ${ }^{5}$
}

\begin{abstract}
Background: Parents play a pivotal role in adolescent sexual health and Human Papillomavirus (HPV) vaccination. Nurses are on the frontlines of healthcare and play a critical role in promoting HPV vaccination and parent-child sexual health communication. We enhanced the Families Talking Together (FTT) parent-based sexual health curriculum to include adolescent vaccinations herein, FTT + HPV, and trained student nurses to provide a strong HPV vaccination and parent-child sexual health communication endorsement.

Methods: Using a randomized attention-controlled trial design, we examined the efficacy of FTT + HPV among 519 parents and their 11-14 year old youth recruited from medically underserved communities between 2015 and 2018. Participants were recruited from 22 after-school programs (e.g., Boys and Girls Clubs) and 19 charter schools. For parents, we examined protective factors including parent-child sexual health communication and parental involvement. For youth, we examined sexual health knowledge, parent-child sexual health communication, and parent-child connectedness. To assess HPV vaccination initiation and completion, we searched IMMTRAC immunization registry records for $85 \%$ of youth and used parental report for youth without registry records. Group differences were calculated using the estimated mean difference at one- and six months post-intervention with significance set at the $p<0.05$ level.

Results: Baseline rates of HPV vaccination were low at $55.7 \%$. No significant difference between the groups was seen in vaccination initiation or completion rates by one-month post-intervention. However, by six-months post intervention, there was a significant difference between the groups with $70.3 \%$ of the intervention group initiating the HPV vaccination series vs. $60.6 \%$ for the control group ( $p=0.02$ ). No difference between the groups was found for HPV series completion at six-months. There were significant differences in condom knowledge $(p=0.04)$, parent-child connectedness $(p=0.04)$, and communication frequency $(p=0.001)$ with greater improvement in the intervention vs. the control group. Rates of sexual activity remained low in both groups throughout the six-month follow-up period.

(Continued on next page)
\end{abstract}

\footnotetext{
*Correspondence: diane.m.santamaria@uth.tmc.edu

${ }^{1}$ University of Texas Health Science Center at Houston, Cizik School of Nursing, 6901 Bertner Ave, Houston, TX, USA

Full list of author information is available at the end of the article
}

(c) The Author(s). 2021 Open Access This article is licensed under a Creative Commons Attribution 4.0 International License, which permits use, sharing, adaptation, distribution and reproduction in any medium or format, as long as you give appropriate credit to the original author(s) and the source, provide a link to the Creative Commons licence, and indicate if changes were made. The images or other third party material in this article are included in the article's Creative Commons licence, unless indicated otherwise in a credit line to the material. If material is not included in the article's Creative Commons licence and your intended use is not permitted by statutory regulation or exceeds the permitted use, you will need to obtain permission directly from the copyright holder. To view a copy of this licence, visit http://creativecommons.org/licenses/by/4.0/ The Creative Commons Public Domain Dedication waiver (http://creativecommons.org/publicdomain/zero/1.0/) applies to the data made available in this article, unless otherwise stated in a credit line to the data. 
(Continued from previous page)

Conclusion: A brief parent-based adolescent sexual health and HPV vaccination intervention delivered by student nurses can improve sexual health outcomes including protective parental factors, adolescent sexual health knowledge, and HPV vaccination initiation rates.

Trial registration: ClinicalTrials.gov Identifier: NCT02600884. Prospectively registered September 1, 2015.

Keywords: Human papillomavirus, HPV vaccine, Parent-child sexual health communication, Parental connectedness, Adolescent sexual behavior

\section{Background}

Puberty is considered the beginning of human sexual development consisting of physical and emotional maturity marking the transition from childhood to adulthood. While engaging in sexual activity is a normal behavior, early sexual activity is associated with negative outcomes including unplanned pregnancy and sexual transmitted infections [1]. About $20 \%$ of 9 th graders in the U.S. report being sexually active [18]. Early sexual debut is associated with inconsistent and nonuse of contraceptives and is a risk factor for sexually transmitted infections (STIs) and pregnancy [20, 22]. Each year in the U.S., adolescents account for nearly half of new STI cases (costing $\$ 6.5$ billion) and experience about 750,000 pregnancies costing $\$ 11$ billion [2, 15, 16, 38]. Adolescents experience the largest burden of STIs, HIV, and unplanned pregnancy in the U.S. [10, 25] with a birth rate of 18.8 per 1000 adolescents $15-19$ years old in 2017 [24]. Human papillomavirus (HPV) continues to be the most common STI in both men and women in the U.S. [31]. Despite the Centers for Disease Control and Prevention $(\mathrm{CDC})$ vaccination guidelines and the widespread availability of free vaccination programs for males and females, initiation and completion rates remain far below the CDC goal of $80 \%$ among early adolescents [33].

There are more than 100 different HPV viral types [31] with 80 million men and women currently infected with at least one type of HPV in the U.S. and 14 million Americans becoming newly infected every year [7]. The average lifetime probability of HPV is $84.6 \%$ for women and $91.3 \%$ for men, with more than $80 \%$ acquiring HPV by age 45 [3]. Of those infected with HPV, $4.9 \%$ were infected with high-risk strains known for causing cancer [26]. Additionally, disparities exist among racial and ethnic minorities in the U.S. with the prevalence of genital and oral HPV infection being higher in the nonHispanic black population than Hispanic and White populations [26]. This is particularly important as Hispanic and non-Hispanic black women have the highest incidence rates of HPV-associated cancers than women in all other ethnic and racial groups. Disparities in HPV vaccination also exist. Among youth $13-17$ years old in the 2008-2009 National Immunization Survey-Teen
( $n=18,228)$, Hispanic and Black youth were less likely than White youth to complete the HPV series [9].

HPV vaccination completion rates vary across states with rates in Texas being among the lowest and remaining lower (39.7\%) than the national average (48.6\%) [37]. In addition to the benefits of state issued vaccination mandates [11], research also demonstrates that simple, cost effective methods such as communication and following vaccination guidelines at age specific visits for adolescents are effective at increasing vaccination rates. Lu et al. [21] found that vaccine recommendations by healthcare providers caring for adolescent males 13-17 increased HPV utilization in Texas [21]. Additionally, adolescents were more likely to initiate the HPV series when the vaccine was bundled with other recommended vaccine(s) [21] and when endorsed by their provider [28].

Parents play a pivotal role in adolescent sexual health and HPV vaccination of adolescents. Educational programs that target parents aim to reduce sexual risk behaviors among adolescents such as early sexual debut and condomless sex by increasing parental protective factors such as parent-child sexual health communication [39], parental monitoring [4], and HPV vaccination rates [8]. In a meta-analysis of parent-child sexual health interventions, intervention participants were $68 \%$ more likely than the control group to report increased communication (Cohen's d, 0.5) and also 75\% more likely to report increased comfort with sexual health communication (Cohen's d, 0.7) [30]. These effects were positive regardless of delivery mode or intervention dose indicating that even brief interventions can also improve parental protective factors [30].

\section{Theoretical framework}

This intervention aimed to reduce adolescent sexual risk behaviors and increase HPV vaccination by bolstering parental protective factors as demonstrated by Hutchinson's parent-based expansion of the theory of planned behavior [19]. This framework posits that parents are more likely to discuss sexual health with youth if they have intentions to communicate, have positive beliefs about parent-child communication (behavioral beliefs), believe that others 
important to them approve of sexual health communication (normative beliefs), and feel that they have the skills needed (control beliefs) to effectively communicate about sexual health topics.

The purpose of the study was to evaluate the efficacy of a brief parent-based adolescent sexual health intervention on parental protective factors and HPV vaccination rates. The intervention was conducted by student nurse facilitators with parents of 11-14 year old youth from medically underserved communities.

\section{Methods}

\section{Recruitment}

Parents and caregivers of youth 11-14 years of age were recruited from 22 after-school programs (e.g. Boys and Girls Clubs) and 19 charter schools in medically underserved communities between 2015 and 2018. Written informed consent was received from the parent participants and written assent was received from the youth. All study procedures were approved from the Committee for the Protection of Human Subjects at the University of Texas Health Science Center at Houston (HSC-SN-15-0091) prior to recruitment and enrollment of study participants. Student research assistants enrolled youth as dyads with their parent and randomly assigned dyads using a computerized random number generator to either the intervention or control group using a 1:1 group allocation. At follow-up, the study team research assistants were blinded to group assignment. Parents and youth received $\$ 20$ for each completed survey.

First, we used community-based participatory methods to adapt Families Talking Together (FTT) to include a module on adolescent vaccinations and HPV specifically. FTT + HPV has three main components: a brief face-toface session, a take-home manual, and booster calls. FTT has been successful in delaying sexual debut in minority youth at nine months post-intervention when implemented in clinics and schools [13, 14]. Importantly, it is available in English and Spanish.

Nurses are the largest frontline healthcare provider workforce and well-positioned to deliver health promoting interventions in community settings. To build on this expertise, we wanted to assess the delivery of FTT + HPV by student nurses [29]. Therefore, we recruited undergraduate senior level student nurses from a public health nursing clinical course who received approximately $32 \mathrm{~h}$ of extensive training on the implementation of the FTT + HPV program and community-based research to serve as the interventionists. Training included Protection of Human Subjects certification, parent-based adolescent sexual health, STIs and HPV, HPV vaccination, and health education communication methods and strategies.

\section{Intervention description}

In the face-to-face session, the parent and student nurse met for approximately $45 \mathrm{~min}$ to review the FTT + HPV materials, motivate parents to talk with their children, and address specific components of the program. Student nurses helped parents designate a time to talk with their children and reviewed information about the context of the present-day teen's world (e.g., physical changes, teen thinking, peers, emotions, and teen moral development) and how a parent can help a teen through positive parenting (e.g., parenting styles, child discipline, parental monitoring, communication, relationship building, forming healthy relationships, self-esteem, refusal and negotiation skills, and risk reduction strategies). The student nurse reviewed information about adolescent vaccinations including the importance of the HPV vaccine, presented local resource materials detailing where and when the child can get vaccinated, and helped the parent make an appointment for vaccination when onsite vaccination clinics were available. Each parent received a manual that reiterated the above-mentioned information as well as three handouts to supplement the face-to-face session. The handouts discussed adolescent vaccinations, contraceptives, and healthy relationships. Parents were encouraged to work through the activities in the manual with their child over the following weeks.

The manual was divided into sections covering health and social consequences of premature sexual behaviors, positive parental influences on adolescent sexual behaviors, saying 'no' to sex, common teen beliefs about sex, monitoring and supervision strategies, parent-child relationship building, and communication tips. Two follow-up telephone-based booster calls were delivered at one- and three-months post-intervention. During the booster session call, the student nurse discussed the parent's progress with communication and vaccination and discussed barriers they were facing while progressing through the manual with their child. Bilingual nursing students were assigned to participants who preferred to receive the intervention discussion or materials in Spanish. When possible, we coordinated with a local pediatric mobile vaccination clinic to offer all childhood vaccinations free of charge through the Vaccines for Children program during the recruitment events. A total of seven vaccination events were coordinated.

The attention control group parents received information from the student nurse on promoting healthy nutrition and exercise among adolescents in a 45-min session. During the session, the student nurse and the parent set a goal related to nutrition and physical activity for their child. Parents also received a brochure of healthy lifestyles and booster calls and 1- and 3-months post-intervention. Similarly, all materials and sessions were available in English and Spanish. 


\section{Parent measures}

Baseline surveys collected data about parents' demographic characteristics including gender, race/ethnicity, level of education, parental role, annual household income, religiosity, and insurance status. In addition, a battery of psychosocial measures were collected at baseline, one, and six months. The primary behavioral outcomes of interest for parents were parent-child sexual health communication, parental intention to vaccinate their children for HPV, and vaccination uptake and completion rates. Psychosocial determinants known to influence parental practice, sexual health communication, and parental monitoring were secondary outcomes examined in this study, as well as factors associated with HPV vaccine uptake and completion such as vaccine beliefs. Parent communication expectancies associated with parent-youth discussions about sex was assessed using a 15-item scale developed by Dilorio et al. [5]. Each item begins with the stem, "If you talk with your child about sex topics..." and is followed by an expected outcome for parents such as, "you will feel that you did the right thing" or "it would be unpleasant" [5] with options from strongly disagree to strongly agree on a 5-point Likert scale. Parent communication self-efficacy was assessed using a 16-item scale. Sample items from the scale include, "You can always explain to your child what you think about adolescents their age having sex" [6]. Response options ranged from "not sure at all" to "completely sure" on a 7-point Likert scale. Frequency of communication about sex was assessed using an 8-item scale [6]. A sample item is: "In the past month, how often have you talked to your child about how to handle sexual pressure by friends or potential partners?" with a 10point scale ranging from never to 10 times or more. Communication ability was assessed using a single item: "How would you rate your ability to communicate with your child about sexual topics?" [6] on a 7-point scale. Communication openness was defined as the extent to which parents feel comfortable talking to their child about sex and was assessed using an 8-item scale [14] with response options ranged from strongly agree to strongly disagree on a 4-point scale.

Secondary parental outcomes included parental connectedness which was defined as the degree of closeness between a parent and child using a 4-item scale [14]. Parents were asked to respond to the following statement: "Most of the time, your child is warm and loving toward you." Response options ranged from not at all to very much on a 1-5 scale. Parental involvement, actively participating in a child's life, was assessed using a 10item scale [14]. A sample item is, "During the past month, how many times did you and your child do fun things together?" Response options were on a 5-point scale that ranged from "not at all" to "7 or more times."
Parental monitoring was assessed using a 7-item scale [14]. A sample item is: "Do you currently have clear rules or expectations about where your child can go after school?"

Parental vaccine beliefs were assessed using a 22-item scale. Sample items include "Vaccinations protect children from getting diseases from unvaccinated children" and "I am more likely to trust vaccinations that have been around awhile." Response options ranged from disagree to agree on a 5-point scale. Intention to vaccinate was assessed using a single item: "Are you planning to give your child all 3 doses of the HPV series?" This item was scored on a dichotomous scale $(0=$ no, $1=$ yes $)$.

Participant scores for the parent measures were calculated as the mean of the answered items multiplied by the total number of items in the scale. This method addresses missing data by using the scale items that were answered by a participant to calculate their scale score (Newman, 2014). Cronbach's alpha for the parent measures ranged from .74 to .93 .

\section{Youth measures}

At baseline, gender, age, and race/ethnicity were among the sociodemographic variables collected for youth. In addition, a host of behavioral and psychosocial measures were administered at baseline, one- and six-months.

The primary outcomes of interest for youth were sexual activity and HPV vaccine uptake. Youth self-reported whether they had ever engaged in oral, vaginal, or anal sex at baseline, one, and six months. These items were scored on a dichotomous scale $(0=$ no, $1=$ yes $)$. Youth also reported frequency of sexual behavior in the past month which was scored on a 6-point Likert scale ranging from never to more than 10 times. To assess HPV vaccine initiation and completion, vaccination records were obtained from IMMTRAC, a state-wide vaccination registry. Records were available for most youth in the study (85\%); parental report was used for the $15 \%$ of youth whose vaccination records were not listed in the registry.

Secondary outcomes known to influence adolescent sexual behavior we also assessed.

Beliefs about sex were assessed using a 4-item scale [34]. A sample item is: "I believe people my age should wait until they are older to have sex." Beliefs about abstinence were examined with a 6-item scale [34]. For example, youth were asked to respond to the following statement: "The best way for young people to avoid an unwanted pregnancy is to wait until they are married before they have sex." Perceived parents beliefs about sex were assessed with a 4-item scale [34]. A sample item from the scale is "My caregiver believes people my age should wait until they are older before they have sex." 
Response options for these 3 scales ranged from strongly agree to strongly disagree on a 1-4 scale.

Self-efficacy for refusing sex was examined using a 7item scale [6]. Each item begins with the stem "Could you stop the person that you like from..." which is followed by intimate behaviors such as "kissing you on the lips, if you did not want them to do that" or "touching your private parts below the waist, if you did not want them to do that." Response options were on a 4point scale and ranged from definitely could not to definitely could. Condom knowledge was assessed with a 6item scale [32]. Sample items include: "Do condoms help keep a person from getting pregnant?" with response options of "Yes," "No" or "Not sure." Condom self-efficacy was assessed using a 4-item scale [34]. A sample is: "How sure are you that you could tell your partner you want to use condoms?" Youth responded on a 1-3 scale ranging from "not at all sure" to "definitely sure." Exposure to risky situations was assessed using a 6-item scale [6]. Each item begins with the stem "In the past month, how often have you...." and is followed by a scenario which might make a youth vulnerable such as "gone to, or stayed at, a party where alcohol was being used". Response options ranged from "never" to "daily" on a 7point scale.

HIV/STI knowledge was assessed with a 5-item scale [6]. A sample is: "You can tell if a person has HIV or AIDS just by looking at them." Response options for youth were true, false, or not sure. Intentions towards sex were examined using a 5-item scale [6]. Each item begins with the stem "How likely is it that you will...." and is followed by statements such as "have oral sex in the next year" or "remain sexually abstinent from now until the marriage" on a 1-5 scale. Expectancies for youth were assessed using a 21-item scale that inquired about how the youth would feel if he/she had sexual intercourse at this point in life and included "it would be embarrassing for me if I got pregnant or got a girl pregnant" or "I would feel more attractive" using a 5-point scale from agree to disagree [6].

Communication self-efficacy can be defined as a youth's level of comfort with talking to their parent about sex and was assessed using a 16-item scale [14]. Each item begins with the stem "How sure are you that you can talk to your caregiver about..." followed by topics like "where to buy or get condoms" or "how to tell a boy/girl no if you do not want to have sex" on a 1-4 scale. Communication about sex outcome expectancy was assessed using a 15 item-scale [6]. A sample item was "If you talk with your caregiver about sex topics you will feel responsible" using a 5-point scale from strongly disagree to strongly agree. Communication about sex was assessed with 8-items examining the content of parent-youth sexual health discussions [17]. Youth were asked questions like "Have you ever talked to your caregiver about when to start having sex" with response options of yes and no. Communication ability was examined using a single item from Schuster et al. [32]: How would you rate your ability to communicate with your caregiver about sexual topics [32]? Youth responded on a 7-point scale ranging from excellent to terrible. Communication content and frequency was assessed by 21-items examining parent-youth sexual health communication [6]. Each item begins with the stem "How many times has your caregiver ever talked to you about..." followed by topics such as "how you will make decisions about whether to have sex" on a 1-5 scale ranging from never to 10 times or more.

Parent-youth connectedness was assessed using a 5item scale [14]. Sample items include: "How close do you feel to your caregiver?" with response options from 1 to 5. Parental monitoring was examined using 5-items that measured youths' perception of parents' knowledge about what the youth is doing, who they are with, and where they are in their free time [14]. A sample item is: "How much does your caregiver know about who your friends really are?" with responses on a 4-point scale. Intentions and beliefs about child disclosure about sex was assessed using a 4-item scale. A sample is: "I plan to talk to my caregiver about sexual health issues in the future" with response options on a 5-point scale.

Participant scores for the youth measures were also calculated as the mean of the answered items multiplied by the total number of items in the scale. Cronbach's alpha for the youth measures ranged from .71 to .95 , except for the intentions towards sex scale, which had a reliability measure of 63 .

\section{Statistical analyses \\ Sample size}

The primary research question is the effectiveness of FTT + in decreasing the proportion of students initiating sexual activity. A sample size (530 adolescent-parent dyads) was calculated to ensure adequate power to test for differences between the intervention and control groups in sexual activity at 6 months. We estimate a participation rate of $85 \%$ or higher based on anticipated community support and the use of incentives. Assuming an attrition rate of $15 \%$, a final sample size of 450 was indicated as needed. Based on this sample size, a chisquare test will have $80 \%$ power when the effect size is $\mathrm{h}=.27$, or when the proportion of intervention and control participants engaging in sexual activity at 6 months is .12 and .22 , respectively.

Descriptive statistics were calculated for demographic variables and instrument scores at each time point. Reliability estimates of the instruments were computed with Cronbach's alpha. Inferential statistical analysis was 
based on the intention-to-treat principle and included all participants who were randomly assigned. The chisquare test was used to compare the groups for sexual behavior and HPV vaccination at each time point. Repeated measures analysis with linear mixed models was used to compare the groups for change over time in the mean instrument scores.

Linear mixed models include all participants with one or more observations in the analysis, with estimates of change in the outcomes based on all observable data. This increases power by allowing for all available data to be included in the analysis. In addition, this reduces bias by including all available data from those that were lost to follow-up in the calculations of the estimates. Linear mixed models were also used to conduct sensitivity analysis to assess the impact of missing data through loss to follow-up (see supplemental materials). These models did not show significant differences for change in parental and youth outcomes due to loss to follow-up (all $p>.18)$.

Logistic regression models were used to test if the interaction of parental communication and parental monitoring was associated with youth sexual behavior at six months. As three parental communication measures were collected, separate models were tested for each. Statistical analyses were conducted with SAS 9.4 for Windows. Group differences were calculated using the estimated mean difference at one- and six-months post intervention with significance set at the $p<0.05$ level. This study adheres to CONSORT guidelines and includes a completed CONSORT checklist as an additional file.

\section{Results}

We screened 557 parent/child dyads for this study of which 519 parents and 508 youth completed the baseline survey and fully enrolled (see Figs. 1 and 2). At 1-month follow-up, 116 parents and 94 youth were lost to followup (i.e. unable to contact participant or complete the survey on time). At 6-months, 122 parents and 111 youth were lost to follow-up.

\section{Sample characteristics}

Parents $(n=519)$ were primarily female $(90.3 \%)$, Hispanic $(56.8 \%)$ or Black (38.3\%), and had some college education (44.9\%) (Tables 1 and 2). The majority of parents identified as mothers (81.9\%), though fathers (5.6\%) and grandparents $(4.1 \%)$ also participated with the remaining caregivers identifying as foster, adoptive, and step-parents. There were no differences in parental role distribution among the intervention and control groups. The largest proportion of participants had Medicaid (42.1\%) with $15 \%$ indicating they had no insurance coverage. Youth $(n=508)$ were on average 12.6 years old, 50.8\% female, and primarily youth of color (54.3\% Hispanic, $40.9 \%$ Black). Most youth were in either 6th $(30.7 \%)$ or 7 th $(27.1 \%)$ grade at baseline.

\section{Parent outcomes}

Parent-child sexual health communication expectancy, self-efficacy, frequency, ability, and openness were analyzed for intervention effects on the change in mean score between intervention and control participants (Table 3). Improvements in parental communication frequency was found at one- and six-months post intervention though no significant difference in expectancy, selfefficacy, ability, or openness. A significant intervention effect was found for communication frequency with a larger mean score increase in frequency among the intervention group $(p=0.001)$. While there was no significance difference in parent reported parent-child connectedness, there were significant differences in parental involvement between the groups with a higher mean score increase found among intervention parents $(p=$ 0.02). No significant differences were found for other parental reported communication measures including parent child sexual health communication expectancy, parent-child communication self-efficacy, communication ability, or openness. There were also no significant intervention effect on parental monitoring.

\section{Youth outcomes}

Improvements in youth knowledge, communication, and parent-child connectedness were noted (Table 4). Specifically, there was a higher mean score increase in condom knowledge among youth in the intervention group compared to control group $(p=0.04)$. Additionally, intervention group youth had significantly larger improvements in youth reported parent-child connectedness compared to control group youth $(p=0.04)$. Finally, measures of parent-child sexual health communication content and frequency significantly differed with a larger mean difference increase among intervention group youth $(p=$ 0.001). No significant differences were found in STI/HIV knowledge, beliefs about sex or abstinence, self-efficacy to refuse sex use a condom. Regarding youth perceptions of parental beliefs, there were no differences in perceived parental beliefs about sex. Rates of sexual activity also remained low throughout the six-month follow-up period with no significant differences in rates of oral, vaginal, or anal sex between youth in the intervention and control groups (Table 4). Less than $2 \%$ of youth reported oral, vaginal, or anal sex at baseline. While a small increase was seen during the follow-up period, at six months, less than $3.5 \%$ of youth reported being sexually active with no differences seen among the two groups. 


\section{CONSORT Flow Diagram - FTT+HPV Study}

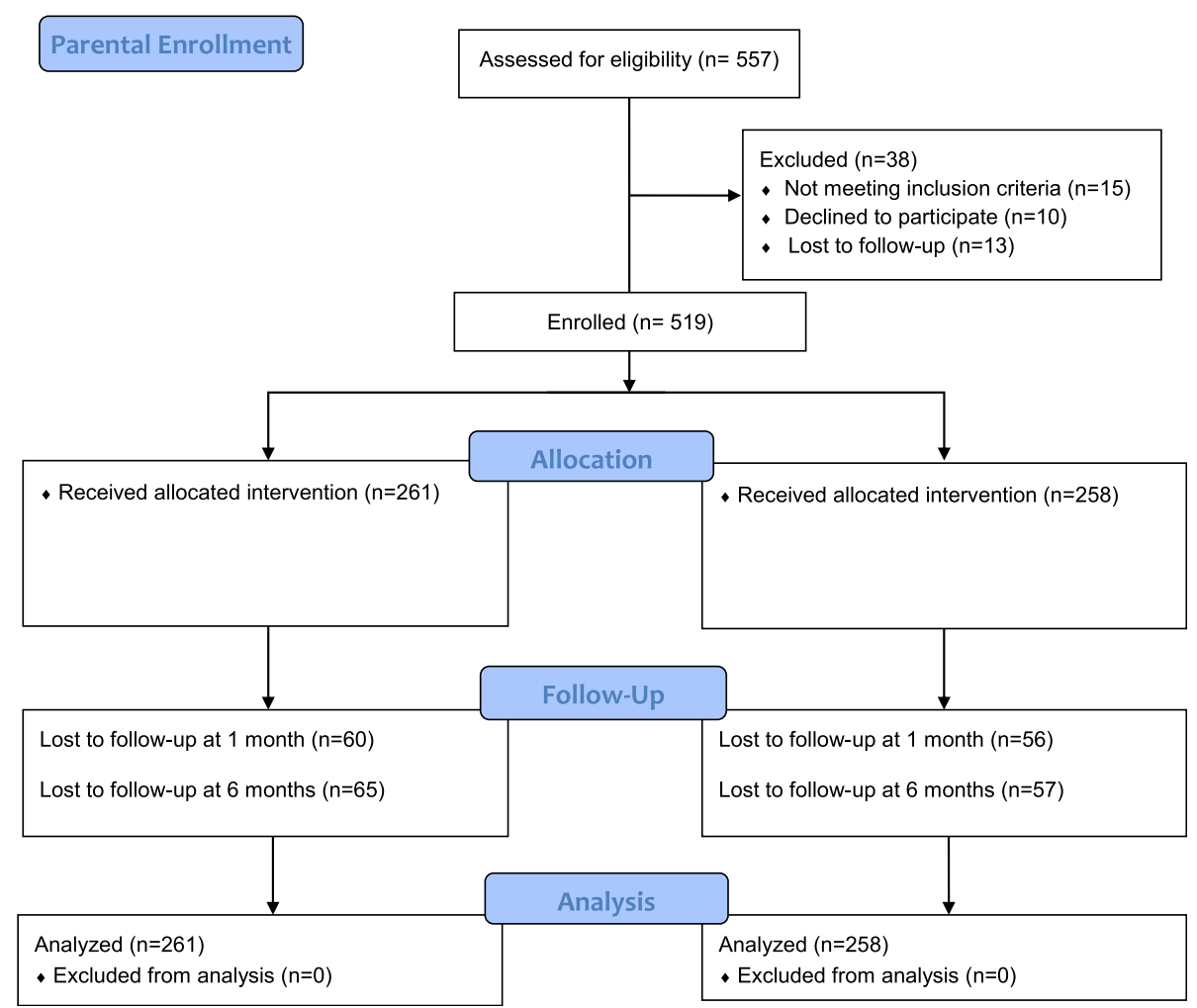

Fig. 1 CONSORT Flow Diagram Parents - FTT + HPV Study

\section{HPV vaccination status}

Baseline rates of HPV vaccination were low (initiation = $55.7 \%$, completion $=34.16 \%$ ) with no significant group differences. No significant differences between the groups were found for vaccination initiation or completion rates by one-month post-intervention. However, by six months post intervention, there was a significant group difference with $70.3 \%$ of the intervention group initiating the HPV vaccination series vs. $60.6 \%$ for the control group $(p=0.02)$. No difference between the groups was found for HPV series completion at six months. However, by six months, the parents in the intervention group were more likely to intend to give their child all three doses of the HPV series (intervention $=72.13 \%$, control $=54.55 \%, p=.0037$ ). There were no differences in vaccination uptake or completion by gender. Although the percentage of girls in the intervention group that initiated the HPV vaccination by six months is higher than boys $(73.02 \%$ vs. $66.06 \%)$, there was no significant difference by gender in HPV vaccination initiation or completion. At six months, $41.8 \%$ of those without vaccination records in the registry reported completing HPV vaccination, compared to $42.3 \%$ of those with records listed in the IMMTRAC registry.

\section{Discussion}

The majority of youth are not yet sexually active by 14 years of age which provides a critical point to intervene and bolster parental protective factors and promote HPV vaccination [35]. Evidence suggests that parentbased sexual health interventions designed to delay premature sex work best when delivered to adolescents prior to the onset of sexual activity [40]. Findings from this study provide further evidence of the efficacy of brief parent-based adolescent sexual health interventions for parents of 11-14 year old youth [30, 40]. This study suggests that a student nurse delivered, parent-based sexual health and HPV vaccination intervention is effective at improving parental protective factors including communication frequency, parental involvement, parentchild connectedness, condom knowledge among youth, and HPV vaccination rates among underserved minority communities. Our findings indicate that this brief intervention was able to increase HPV vaccination uptake compared to the control arm. This is critically important given the low vaccination rates found; over $40 \%$ of youth had not yet started the HPV vaccine series at baseline.

While the effects on parent-child sexual health communication frequency and HPV vaccination uptake were positive, we found no significant intervention effects on 


\section{CONSORT Flow Diagram - FTT+HPV Study}

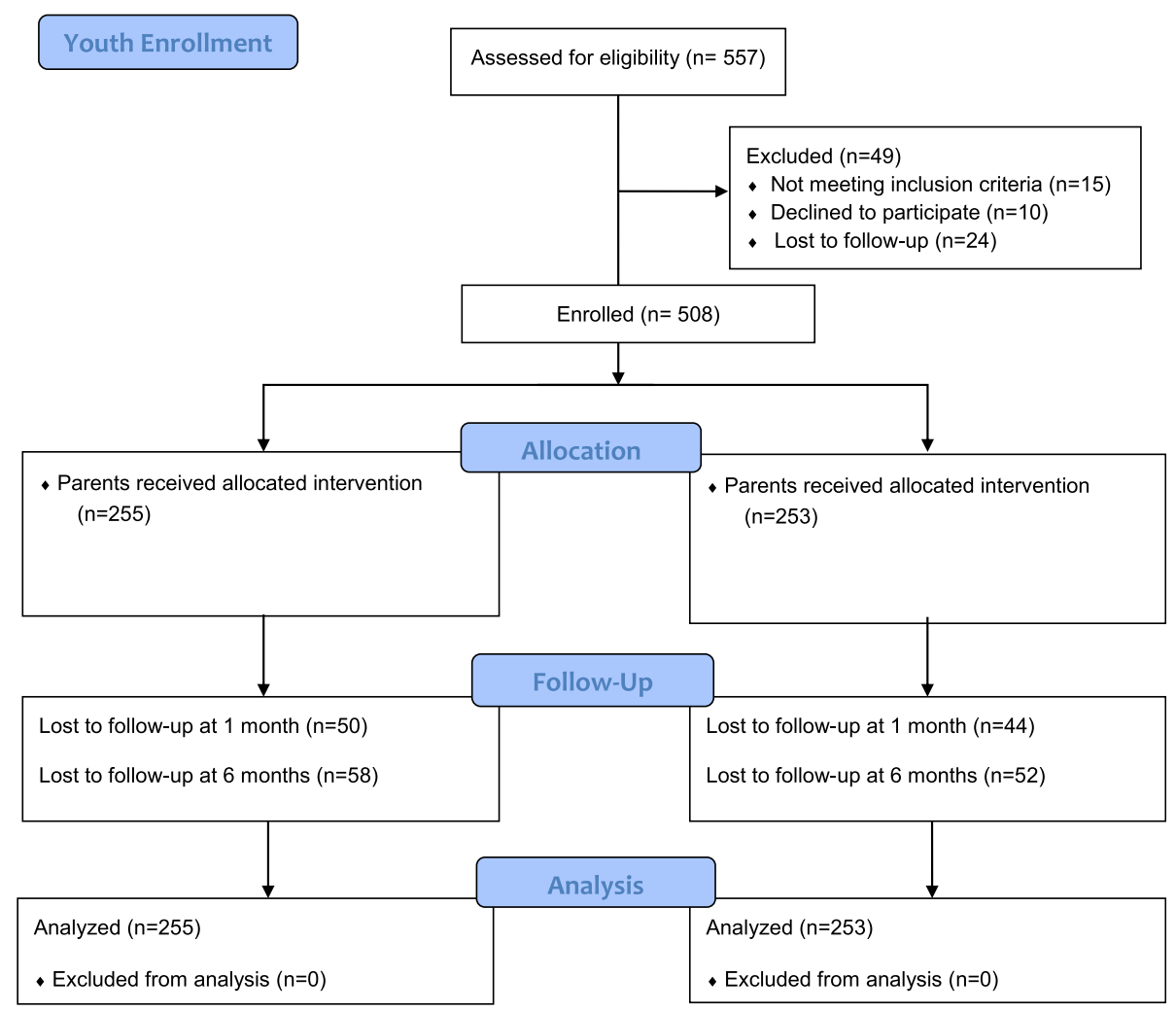

Fig. 2 CONSORT Flow Diagram Youth - FTT + HPV Study

parental monitoring or adolescent sexual activity. Parental monitoring is a well-established parental protective factor for adolescent sexual activity [4, 14]. Despite that the intervention addressed parental monitoring and supervision strategies, baseline rates of monitoring from both the parent and youth measures were already high making it difficult to assess for improvements. Finally, very few youth initiated sexual activity during the study period making it difficult to detect group differences at six-months.

Given the intervention effects on communication and connectedness and the positive mediating effect of parent-child sexual health communication [30] and connectedness [23], it was surprising to see little evidence of intervention impact on adolescent sexual behaviors. However, this is likely due to the low levels of sexual activity at baseline and follow-up among this sample of adolescents making it difficult to detect behavioral changes on sexual behavior. A recent meta-analysis found that intervention effects on adolescent sexual behavior are stronger when the intervention is longer, developmentally and culturally tailored to the specific target groups, and includes components for both parents and youth [40]. Therefore, a longer intervention follow-up period and inclusion of youth with greater variability in the onset and frequency of sexual behavior may increase the ability to assess intervention effects on delay of sex and condom use [12].

While both parents and youth reported improvements in communication frequency, there was discordance among the parent-child dyads regarding connectedness, an important factor in parent-youth measurement [41]. While there were no significant intervention effects among parents, there was a significant improvement in youth reported connectedness among the intervention group. Additionally, while no difference in connectedness was found among parents, there was a significant improvement in youth reports of parental involvement between the intervention and control groups.

Notably, this intervention can be delivered in approximately $45 \mathrm{~min}$ with two brief follow-up calls. Therefore, the ease of delivery may improve access to and uptake of parent-based interventions. Finding creative ways of addressing the burden of participation for parents such as delivering interventions where parents are at in their daily routine may increase the reach into underserved communities [12]. Other venues that should be explored are school pick-up lines common in some communities, 
Table 1 Parent Baseline Socio-Demographic Characteristics by Condition

\begin{tabular}{|c|c|c|c|c|}
\hline Characteristic & Total Parent Sample & Parent Intervention Group & Parent Control Group & $P$ Value \\
\hline Sample Size & 519 & 261 & 258 & \\
\hline Gender & & & & .74 \\
\hline Male & $50(9.73 \%)$ & $24(9.30 \%)$ & $26(10.16 \%)$ & \\
\hline Female & $464(90.27 \%)$ & $234(90.70 \%)$ & 230 (89.84\%) & \\
\hline Race/Ethnicity & & & & .56 \\
\hline African American & 199 (38.34\%) & $102(39.08 \%)$ & $97(37.60 \%)$ & \\
\hline Hispanic & 295 (56.84\%) & $147(56.32 \%)$ & $148(57.36 \%)$ & \\
\hline White & $14(2.70 \%)$ & $5(1.92 \%)$ & $9(3.49 \%)$ & \\
\hline Other & $11(2.12 \%)$ & $7(2.68 \%)$ & $4(1.55 \%)$ & \\
\hline Education & & & & .20 \\
\hline Did Not Finish High School & $96(18.71 \%)$ & $53(20.54 \%)$ & $43(16.86 \%)$ & \\
\hline High School Graduate & $121(23.59 \%)$ & $61(23.64 \%)$ & $60(23.53 \%)$ & \\
\hline Vocational/Technical & $66(12.87 \%)$ & $32(12.40 \%)$ & $34(13.33 \%)$ & \\
\hline Some College & 119 (23.20\%) & $63(24.42 \%)$ & $56(21.96 \%)$ & \\
\hline College Graduate & $111(21.64 \%)$ & $49(18.99 \%)$ & $62(24.31 \%)$ & \\
\hline Insurance Status & & & & .36 \\
\hline None & $81(15.70 \%)$ & $44(16.92 \%)$ & $37(14.45 \%)$ & \\
\hline Medicaid & $217(42.05 \%)$ & $116(44.62 \%)$ & $101(39.45 \%)$ & \\
\hline Private & 168 (32.56\%) & $76(29.23 \%)$ & 92 (35.94\%) & \\
\hline Other & $50(9.69 \%)$ & $24(9.23 \%)$ & $26(10.16 \%)$ & \\
\hline
\end{tabular}

Table 2 Youth Baseline Socio-Demographic Characteristics by Condition

\begin{tabular}{|c|c|c|c|c|}
\hline Characteristic & Total Youth Sample & Youth Intervention Group & Youth Control Group & $P$ Value \\
\hline Sample Size & 508 & 255 & 253 & \\
\hline Mean Age (sd) & $12.57(1.17)$ & $12.58(1.22)$ & $12.57(1.11)$ & .88 \\
\hline Gender & & & & .25 \\
\hline Male & 247 (49.20\%) & $117(46.61 \%)$ & $130(51.79 \%)$ & \\
\hline Female & $255(50.80 \%)$ & $134(53.39 \%)$ & $121(48.21 \%)$ & \\
\hline Race/Ethnicity & & & & .46 \\
\hline African American & 208 (40.94\%) & $112(43.92 \%)$ & 96 (37.94\%) & \\
\hline Hispanic & $276(54.33 \%)$ & $131(51.37 \%)$ & $145(57.31 \%)$ & \\
\hline White & $12(2.36 \%)$ & $5(1.96 \%)$ & $7(2.77 \%)$ & \\
\hline Other & $12(2.36 \%)$ & $7(2.75 \%)$ & $5(1.98 \%)$ & \\
\hline Attending School & & & & 1.0 \\
\hline Yes & $498(99.40 \%)$ & $249(99.20 \%)$ & $249(99.60 \%)$ & \\
\hline No & $3(0.60 \%)$ & $2(0.80 \%)$ & $1(0.40 \%)$ & \\
\hline Current Grade & & & & .56 \\
\hline 4th & $5(1.00 \%)$ & $4(1.59 \%)$ & $1(0.40 \%)$ & \\
\hline 5 th & 85 (16.93\%) & $51(20.32 \%)$ & $34(13.55 \%)$ & \\
\hline 6 th & $154(30.68 \%)$ & 69 (27.49\%) & 85 (33.86\%) & \\
\hline 7th & 136 (27.09\%) & $63(25.10 \%)$ & 73 (29.08\%) & \\
\hline 8th & 99 (19.72\%) & $48(19.12 \%)$ & $51(20.32 \%)$ & \\
\hline 9th & $23(4.58 \%)$ & $16(6.37 \%)$ & 7 (2.79\%) & \\
\hline
\end{tabular}


Table 3 Parent Child Communication, Monitoring, Connectedness, and HPV Vaccine Beliefs by Condition and Assessment Period (Means and Standard Deviations)

\begin{tabular}{|c|c|c|c|c|}
\hline \multicolumn{5}{|l|}{ Parental Outcomes } \\
\hline Variable & Baseline $(n=519)$ & 1-Month $(n=403)$ & 6-Month $(n=397)$ & $P$ Value ${ }^{1}$ \\
\hline \multicolumn{5}{|l|}{ Primary Parent Outcomes } \\
\hline \multicolumn{2}{|c|}{ Parent Communication Expectancy } & & & .85 \\
\hline Intervention Group & $57.27(7.83)$ & $57.93(7.44)$ & $58.16(8.64)$ & \\
\hline Control Group & $57.58(8.16)$ & $57.75(8.30)$ & $58.18(8.75)$ & \\
\hline \multicolumn{2}{|c|}{ Parent Communication Self-Efficacy } & & & .21 \\
\hline Intervention Group & $89.01(17.87)$ & $93.02(16.05)$ & $95.92(15.41)$ & \\
\hline Control Group & $90.15(18.17)$ & $93.82(15.26)$ & $93.98(16.34)$ & \\
\hline \multicolumn{2}{|c|}{ Frequency of Communication } & & & .001 \\
\hline Intervention Group & $17.18(13.54)$ & $23.89(16.54)$ & $25.89(17.77)$ & \\
\hline Control Group & $18.09(14.86)$ & $20.67(15.28)$ & $21.63(17.05)$ & \\
\hline \multicolumn{2}{|l|}{ Communication Ability } & & & .49 \\
\hline Intervention Group & $2.90(1.41)$ & $2.49(1.19)$ & $2.41(1.21)$ & \\
\hline Control Group & $2.92(1.50)$ & $2.70(1.32)$ & $2.57(1.33)$ & \\
\hline \multicolumn{2}{|c|}{ Communication Openness } & & & .19 \\
\hline Intervention Group & $17.10(4.84)$ & $15.09(4.14)$ & $14.90(4.13)$ & \\
\hline Control Group & $16.88(4.57)$ & $15.74(4.06)$ & $15.10(4.66)$ & \\
\hline \multicolumn{5}{|c|}{ Secondary Parent Outcomes } \\
\hline \multicolumn{2}{|c|}{ Parent-Child Connectedness } & & & .65 \\
\hline Intervention Group & $17.82(2.74)$ & $17.96(3.00)$ & $18.16(2.73)$ & \\
\hline Control Group & $17.35(2.87)$ & $17.28(3.06)$ & $17.63(2.90)$ & \\
\hline \multicolumn{2}{|l|}{ Parental Involvement } & & & .02 \\
\hline Intervention Group & $35.28(5.27)$ & $36.29(4.72)$ & $36.77(4.56)$ & \\
\hline Control Group & $35.64(5.55)$ & $35.56(5.63)$ & $36.00(5.36)$ & \\
\hline \multicolumn{2}{|l|}{ Parental Monitoring } & & & .45 \\
\hline Intervention Group & $7.34(0.87)$ & $7.35(0.99)$ & $7.24(0.80)$ & \\
\hline Control Group & $7.42(1.09)$ & $7.32(0.96)$ & $7.23(0.75)$ & \\
\hline \multicolumn{2}{|l|}{ HPV Vaccine Beliefs } & & & .64 \\
\hline Intervention Group & $82.33(11.68)$ & $84.08(11.22)$ & $84.03(12.62)$ & \\
\hline Control Group & 82.64 (11.59) & $83.67(11.04)$ & $83.35(11.54)$ & \\
\hline \multicolumn{5}{|c|}{ Secondary Youth Outcomes } \\
\hline Variable & Baseline $(n=508)$ & 1-Month $(n=414)$ & 6-Month $(n=397)$ & P Value ${ }^{1}$ \\
\hline \multicolumn{2}{|l|}{ Beliefs About Sex } & & & 0.33 \\
\hline Intervention Group & $14.06(2.16)$ & $13.83(2.20)$ & $13.56(2.47)$ & \\
\hline Control Group & $14.09(2.18)$ & $13.87(2.37)$ & $13.37(2.48)$ & \\
\hline \multicolumn{2}{|l|}{ Beliefs About Abstinence } & & & 0.33 \\
\hline Intervention Group & $18.00(4.19)$ & $17.65(4.68)$ & $18.07(4.24)$ & \\
\hline Control Group & $18.29(3.87)$ & $18.26(4.35)$ & $18.02(4.17)$ & \\
\hline \multicolumn{2}{|c|}{ Perceived Parents Beliefs About Sex } & & & 0.64 \\
\hline Intervention Group & $14.37(2.14)$ & $13.95(2.37)$ & $14.14(2.27)$ & \\
\hline Control Group & $14.44(2.21)$ & $14.09(2.35)$ & $14.08(2.24)$ & \\
\hline
\end{tabular}


Table 3 Parent Child Communication, Monitoring, Connectedness, and HPV Vaccine Beliefs by Condition and Assessment Period (Means and Standard Deviations) (Continued)

\begin{tabular}{|c|c|c|c|c|}
\hline \multicolumn{5}{|l|}{ Parental Outcomes } \\
\hline Variable & Baseline $(n=519)$ & 1-Month $(n=403)$ & 6-Month $(n=397)$ & $P$ Value \\
\hline \multicolumn{4}{|c|}{ Self-Efficacy for Refusing Sex } & 0.22 \\
\hline Intervention Group & $25.35(4.12)$ & $24.60(5.06)$ & $25.28(4.35)$ & \\
\hline Control Group & $25.07(4.30)$ & $24.93(4.78)$ & $24.69(4.78)$ & \\
\hline \multicolumn{4}{|l|}{ Condom Knowledge } & 0.04 \\
\hline Intervention Group & $28.99(30.33)$ & 32.35 (31.98) & $41.37(35.43)$ & \\
\hline Control Group & $33.20(29.69)$ & $31.13(32.24)$ & $36.55(31.60)$ & \\
\hline \multicolumn{4}{|l|}{ Condom Self-Efficacy } & 0.63 \\
\hline Intervention Group & $7.17(2.56)$ & $7.80(2.60)$ & $8.28(2.50)$ & \\
\hline Control Group & $7.22(2.53)$ & $7.70(2.64)$ & $7.89(2.36)$ & \\
\hline \multicolumn{4}{|c|}{ Exposure to Risky Situations } & 0.33 \\
\hline Intervention Group & $7.24(2.78)$ & $7.81(4.08)$ & $8.01(4.74)$ & \\
\hline Control Group & $7.70(3.88)$ & $7.72(3.70)$ & $7.92(4.43)$ & \\
\hline \multicolumn{4}{|l|}{ HIV/STI Knowledge } & 0.13 \\
\hline Intervention Group & $25.22(29.68)$ & $26.03(32.97)$ & $35.69(35.55)$ & \\
\hline Control Group & $23.94(27.40)$ & $24.22(28.90)$ & $27.41(32.13)$ & \\
\hline \multicolumn{4}{|l|}{ Intentions Toward Sex } & 0.83 \\
\hline Intervention Group & $18.52(4.35)$ & $18.04(4.52)$ & $19.11(4.48)$ & \\
\hline Control Group & $18.49(4.44)$ & $18.52(4.42)$ & $18.92(4.45)$ & \\
\hline \multicolumn{4}{|l|}{ Expectancies } & 0.63 \\
\hline Intervention Group & $80.61(15.61)$ & $76.98(16.34)$ & $77.57(16.04)$ & \\
\hline Control Group & $81.02(16.04)$ & $79.20(17.62)$ & $79.49(15.45)$ & \\
\hline \multicolumn{4}{|c|}{ Communication About Sex Self-Efficacy } & 0.40 \\
\hline Intervention Group & $37.26(14.48)$ & $37.31(15.26)$ & $39.38(15.62)$ & \\
\hline Control Group & $39.23(14.30)$ & $37.79(15.49)$ & $40.69(15.62)$ & \\
\hline \multicolumn{4}{|c|}{ Communication About Sex Outcome Expectancy } & 0.70 \\
\hline Intervention Group & $46.66(9.90)$ & $46.75(9.80)$ & $48.27(8.97)$ & \\
\hline Control Group & $45.53(9.47)$ & $45.70(9.15)$ & $47.90(9.17)$ & \\
\hline \multicolumn{4}{|c|}{ Communication About Sex } & 0.19 \\
\hline Intervention Group & $14.55(11.88)$ & $17.14(15.05)$ & $19.81(17.93)$ & \\
\hline Control Group & $14.57(12.44)$ & $14.78(12.77)$ & $16.96(16.61)$ & \\
\hline \multicolumn{4}{|l|}{ Communication Ability } & 0.09 \\
\hline Intervention Group & $4.39(1.96)$ & $4.64(1.86)$ & $4.71(1.87)$ & \\
\hline Control Group & $4.66(1.80)$ & $4.54(1.86)$ & $4.73(1.77)$ & \\
\hline \multicolumn{4}{|c|}{ Parent-Child Connectedness } & 0.04 \\
\hline Intervention Group & $20.00(5.89)$ & $20.57(5.13)$ & $20.55(5.37)$ & \\
\hline Control Group & $20.79(4.83)$ & $20.32(5.11)$ & $20.97(4.65)$ & \\
\hline \multicolumn{4}{|l|}{ Parental Monitoring } & 0.77 \\
\hline Intervention Group & $15.40(4.55)$ & $15.85(4.39)$ & $16.27(4.46)$ & \\
\hline Control Group & $15.54(4.16)$ & $15.96(4.15)$ & $16.49(3.66)$ & \\
\hline \multicolumn{4}{|c|}{ Intentions and Beliefs About Child Disclosure } & 0.75 \\
\hline Intervention Group & $15.10(4.33)$ & $15.00(4.15)$ & $15.16(4.20)$ & \\
\hline Control Group & $15.21(4.05)$ & $14.96(3.94)$ & $14.95(3.98)$ & \\
\hline
\end{tabular}


Table 3 Parent Child Communication, Monitoring, Connectedness, and HPV Vaccine Beliefs by Condition and Assessment Period (Means and Standard Deviations) (Continued)

\begin{tabular}{|c|c|c|c|c|}
\hline \multicolumn{5}{|l|}{ Parental Outcomes } \\
\hline Variable & Baseline $(n=519)$ & 1-Month $(n=403)$ & 6-Month $(n=397)$ & $P$ Value ${ }^{1}$ \\
\hline \multicolumn{4}{|c|}{ Communication Content and Frequency } & .001 \\
\hline Intervention Group & $2.78(2.03)$ & $3.25(2.50)$ & $4.08(3.05)$ & \\
\hline Control Group & $2.94(2.10)$ & $2.84(2.11)$ & $3.31(2.59)$ & \\
\hline
\end{tabular}

'Interaction of Group*Month comparing change in score between groups

Table 4 Primary Youth Sexual Behaviors by Condition and Assessment Period

\begin{tabular}{|c|c|c|c|}
\hline Variable & No $n(\%)$ & Yes $n(\%)$ & $P$ Value $^{1}$ \\
\hline \multicolumn{4}{|l|}{ Baseline $(n=508)$} \\
\hline Ever Had Oral Sex & & & 0.50 \\
\hline Intervention Group & $250(98.81 \%)$ & $3(1.19 \%)$ & \\
\hline Control Group & $247(98.02 \%)$ & $5(1.98 \%)$ & \\
\hline Ever Had Vaginal Sex & & & 0.12 \\
\hline Intervention Group & $252(99.60 \%)$ & $1(0.40 \%)$ & \\
\hline Control Group & 247 (98.02\%) & $5(1.98 \%)$ & \\
\hline Ever Had Anal Sex & & & 1.00 \\
\hline Intervention Group & 252 (99.60\%) & $1(0.40 \%)$ & \\
\hline Control Group & 251 (99.60\%) & $1(0.40 \%)$ & \\
\hline \multicolumn{4}{|c|}{ 1-Month Follow-Up $(n=414)$} \\
\hline Ever Had Oral Sex & & & 0.72 \\
\hline Intervention Group & $200(98.04 \%)$ & $4(1.96 \%)$ & \\
\hline Control Group & $202(98.54 \%)$ & $3(1.46 \%)$ & \\
\hline Ever Had Vaginal Sex & & & 0.28 \\
\hline Intervention Group & $202(99.02 \%)$ & $2(0.98 \%)$ & \\
\hline Control Group & 199 (97.07\%) & $6(2.93 \%)$ & \\
\hline Ever Had Anal Sex & & & 0.22 \\
\hline Intervention Group & $200(98.04 \%)$ & $4(1.96 \%)$ & \\
\hline Control Group & $204(99.51 \%)$ & $1(0.49 \%)$ & \\
\hline \multicolumn{4}{|c|}{ 6-Month Follow-Up $(n=397)$} \\
\hline Ever Had Oral Sex & & & 0.34 \\
\hline Intervention Group & $194(98.48 \%)$ & $3(1.52 \%)$ & \\
\hline Control Group & $193(96.50 \%)$ & $7(3.50 \%)$ & \\
\hline Ever Had Vaginal Sex & & & 1.00 \\
\hline Intervention Group & $194(98.48 \%)$ & $3(1.52 \%)$ & \\
\hline Control Group & 196 (98.00\%) & $4(2.00 \%)$ & \\
\hline Ever Had Anal Sex & & & 0.37 \\
\hline Intervention Group & 194 (98.48\%) & $3(1.52 \%)$ & \\
\hline Control Group & 199 (99.50\%) & $1(0.50 \%)$ & \\
\hline
\end{tabular}

${ }^{1}$ Chi-square test school registration nights, and school open-house events. Delivery of interventions in the clinic setting and online also demonstrate efficacy [13, 36]. A longer workplace intervention has also shown promise and may suggest the need for assessing the efficacy of delivering a brief parent-based adolescent sexual health intervention in the workplace [32].

The efficacy of this intervention also suggests that student nurses are effective interventionists for parentbased adolescent sexual health among high-risk, underserved populations. In addition to serving the public health goals of promoting adolescent sexual health and improving HPV vaccination rates, this delivery format allows for action oriented, community-based health promotion learning for student nurses. This is particularly important given the need to address person-centered care and population health as core competencies in undergraduate nursing education.

Despite the promising findings of the intervention, there are study limitations that should be considered when interpreting the findings. Specifically, this study only followed parents and youth for six-months after the intervention. Therefore, longer term sustainability of intervention effects are not known. As well, very few youth in the sample were sexually active at baseline or at the six-month follow-up making detection of intervention effects on sexual behaviors not possible. A longer follow-up period may assist in assessing intervention effects on adolescent sexual activity. The sample was primarily comprised of youth of color and therefore may not be generalizable to populations other than Black and Latino youth and parents. As well, while some fathers and grandparents participated, the large majority of caregivers were mothers with samples too small to examine findings specifically among fathers or grandparents. Further, this intervention may need to be modified for implementation in other countries and cultures. Lastly, the primary outcomes were self-report. Therefore, social desirability in adolescent reports of sexual behavior cannot be ruled out. Future research should include the use of biomarkers (i.e., STI point-of-care test) as an additional measure to adolescent self-report of sexual behavior. 


\section{Conclusion}

Adolescence is a critical time to influence the adoption of lifelong protective behaviors and overall well-being [27]. Therefore, we must continue to research novel methods and strategies to addressing persistent sexual and reproductive health disparities among adolescents, particularly youth of color. Nurses are on the frontlines of healthcare, both highly competent in caring for complex health conditions among individuals and being uniquely positioned in community settings to bridge the gap between health promotion science and implementation across hard-to-reach communities [29]. Student nurses are effective parent-based adolescent sexual health interventionists. Therefore, investing in the training and utilization of student nurses as facilitators of prevention interventions serves our communities and lays the groundwork for effective nursing practice among the largest segment of the healthcare workforce. Further research is needed to examine the impact of delivering evidence-based prevention interventions in the community on the learning satisfaction and clinical competencies of student nurses.

\section{Abbreviations}

HPV: Human papillomavirus; FTT: Families Talking Together

\section{Supplementary Information}

The online version contains supplementary material available at https://doi. org/10.1186/s12889-021-10534-0.

Additional file 1.

\section{Acknowledgements}

We would like to thank the schools and after-school programs where this study took place. A related abstract is published at: Santa Maria D. 8. Efficacy of a Student-Nurse Brief Parent-Based Sexual Health Intervention to Increase HPV Vaccination Among Adolescents. Journal of Adolescent Health. 2020 Feb 1;66(2): S4-5.

\section{Authors' contributions}

DSM, CM, and VGR conceptualized the study. DSM, DC, and SC analyzed and interpreted the data. All authors were major contributors in writing the manuscript and read and approved the final manuscript.

\section{Funding}

This study was supported by a grant awarded to Dr. Santa Maria funded by the National Institutes of Health NICHD (R15HD081364). The funder had no role in the design, data collection, analyses, or interpretation of the findings from this study.

\section{Availability of data and materials}

The datasets during and/or analyzed during the current study available from the corresponding author on reasonable request.

\section{Declarations}

\section{Ethics approval and consent to participate}

All study procedures were approved by the Committee for the Protection of Human Subjects (HSC-SN-15-0091) at the University of Texas Health Science Center at Houston prior to recruitment and enrollment of study participants. Parent participants provided written consent for themselves and their child. Youth participants provided written assent.
Consent for publication

Not applicable.

\section{Competing interests}

The authors declare that they have no competing interests.

\section{Author details}

${ }^{1}$ University of Texas Health Science Center at Houston, Cizik School of Nursing, 6901 Bertner Ave, Houston, TX, USA. ${ }^{2}$ Health Promotion and Behavioral Sciences, University of Texas Health Science Center at Houston School of Public Health, 7000 Fannin Street, Houston, TX, USA. ${ }^{3}$ Baylor College of Medicine, Texas Children's Hospital, 8080 North Stadium Drive, Suite 250, Houston, TX, USA. ${ }^{4}$ Cizik School of Nursing, University of Texas Health Science Center at Houston, Houston, TX, USA. ${ }^{5}$ Center for Latino Adolescent and Family Health, New York University, New York, NY, USA.

Received: 24 August 2020 Accepted: 2 March 2021

Published online: 24 March 2021

\section{References}

1. Baams L, Dubas JS, Overbeek G, van Aken MAG. Transitions in body and behavior: a meta-analytic study on the relationship between pubertal development and adolescent sexual behavior. J Adolesc Health. 2015;56(6): 586-98 https://doi.org/10.1080/00224499.2013.802758.

2. Chesson HW, Blandford JM, Gift TL, Tao G, Irwin KL. The estimated direct medical cost of sexually transmitted diseases among American youth, 2000. Perspect Sex Reprod Health. 2004;36(1):11-9.

3. Chesson HW, Dunne EF, Hariri S, Markowitz LE. The estimated lifetime probability of acquiring human papillomavirus in the United States. Sex Transm Dis. 2014;41(11):660-4.

4. DiClemente RJ, Wingood GM, Crosby R, Sionean C, Cobb BK, Harrington K, Davies S, Hook EW, Oh MK. Parental monitoring: association with adolescents' risk behaviors. Pediatrics. 2001;107(6):1363-8.

5. Dilorio C, Dudley WN, Wang DT, Wasserman J, Eichler M, Belcher L, WestEdwards C. Measurement of parenting self-efficacy and outcome expectancy related to discussions about sex. J Nurs Meas. 2001;9(2):135-49.

6. Dilorio C, Resnicow K, McCarty F, De AK, Dudley WN, Wang DT, Denzmore P. Keepin'it REAL!: results of a mother-adolescent HIV prevention program. Nurs Res. 2006;55(1):43-51.

7. Division of STD Prevention, N. C. f. H. A., Viral Hepatitis, STD, and TB Prevention, Centers for Disease Control and Prevention. Genital HPV Infection - Fact Sheet. 2019. Retrieved February 22, 2020 from https://www. cdc.gov/std/hpv/stdfact-hpv.htm

8. Dixon BE, Zimet GD, Xiao S, Tu W, Lindsay B, Church A, Downs SM. An educational intervention to improve HPV vaccination: a cluster randomized trial. Pediatrics. 2019;143(1):e20181457.

9. Dorell CG, Yankey D, Santibanez TA, Markowitz LE. Human papillomavirus vaccination series initiation and completion, 2008-2009. Pediatrics. 2011; 128(5):830-9.

10. Eaton DK, Kann L, Kinchen S, Shanklin S, Flint KH, Hawkins J, Harris WA Lowry R, McManus T, Chyen D. Youth risk behavior surveillance-United States, 2011. MMWR Surveill Summ. 2012;61(4):1-162.

11. Franco M, Mazzucca S, Padek M, Brownson RC. Going beyond the individual: how state-level characteristics relate to HPV vaccine rates in the United States. BMC Public Health. 2019;19(1):246.

12. Guilamo-Ramos V, Benzekri A, Thimm-Kaiser M. Parent-based interventions to affect adolescent sexual and reproductive health: reconsidering the best evidence vs all evidence. JAMA Pediatr. 2019;173(9):821-3.

13. Guilamo-Ramos V, Bouris A, Jaccard J, Gonzalez B, McCoy W, Aranda D. A parent-based intervention to reduce sexual risk behavior in early adolescence: building alliances between physicians, social workers, and parents. J Adolesc Health. 2011a;48(2):159-63.

14. Guilamo-Ramos V, Jaccard J, Dittus P, Bouris A, Gonzalez B, Casillas E, Banspach S. A comparative study of interventions for delaying the initiation of sexual intercourse among Latino and black youth. Perspect Sex Reprod Health. 2011b;43(4):247-54

15. Hoffman SD. By the numbers: the public costs of teen childbearing. 2006. National Campaign to Prevent Teen Pregnancy.

16. Hoffman SD. Counting it up: the public costs of teen childbearing. 2008

17. Hutchinson MK. The parent-teen sexual risk communication scale (PTSRC-III): instrument development and psychometrics. Nurs Res. 2007;56(1):1-8. 
18. Kann L, McManus T, Harris WA, Shanklin SL, Flint KH, Queen B, Lowry R, Chyen D, Whittle L, Thornton J. Youth risk behavior surveillance-United States, 2017. MMWR Surveill Summ. 2018;67(8):1.

19. Katherine Hutchinson M, Wood EB. Reconceptualizing adolescent sexual risk in a parent-based expansion of the theory of planned behavior. J Nurs Scholarsh. 2007:39(2):141-6.

20. Kirby D, Lepore G, Ryan J. Sexual risk and protective factors. In: Factors affecting teen sexual behavior, pregnancy, childbearing and sexually transmitted disease: which are important? Which can you change. 2005. p. 8.

21. Lu P-J, Yankey D, Fredua B, O'Halloran AC, Williams C, Markowitz LE, ElamEvans LD. Association of Provider Recommendation and Human Papillomavirus Vaccination Initiation among male adolescents aged 13-17 years_United States. J Pediatr. 2019;206:33-41 e31.

22. Magnusson BM, Masho SW, Lapane KL. Early age at first intercourse and subsequent gaps in contraceptive use. J Women's Health. 2012;21(1):73-9.

23. Markham CM, Lormand D, Gloppen KM, Peskin MF, Flores B, Low B, House LD. Connectedness as a predictor of sexual and reproductive health outcomes for youth. J Adolesc Health. 2010;46(3):S23-41.

24. Martin JA, Hamilton BE, Osterman MJK. Births in the United States, 2017. 2018. N. C. f. H. Statistics.

25. Martin JA, Hamilton BE, Ventura SJ, Osterman M, Kirmeyer S, Mathews T, Wilson EC. Births: final data for 2009. National vital statistics reports: from the Centers for Disease Control and Prevention, National Center for Health Statistics, Natl Vital Stat Syst. 2011;60(1):1.

26. McQuillan GM, Kruszon-Moran D, Markowitz LE, Unger ER, Paulose-Ram R. Prevalence of HPV in adults aged 18-69: United States, 2011-2014. Hyattsville, MD: US Department of Health and Human Services, Centers for Disease Control and Prevention, National Center for Health Statistics. (2017).

27. National Academies of Sciences, E, \& Medicine. The promise of adolescence: realizing opportunity for all youth. National Academies Press; 2019.

28. Newman PA, Logie CH, Lacombe-Duncan A, Baiden P, Tepjan S, Rubincam C, Doukas N, Asey F. Parents' uptake of human papillomavirus vaccines for their children: a systematic review and meta-analysis of observational studies. BMJ Open. 2018;8(4):e019206.

29. Santa Maria D, Guilamo-Ramos V, Jemmott LS, Derouin A, Villarruel A. Nurses on the front lines: improving adolescent sexual and reproductive health across health care settings. AJN. 2017;117(1):42-51.

30. Santa Maria D, Markham C, Bluethmann S, Mullen PD. Parent-based adolescent sexual health interventions and effect on communication outcomes: a systematic review and meta-analyses. Perspect Sex Reprod Health. 2015:47(1):37-50

31. Satterwhite CL, Torrone E, Meites E, Dunne EF, Mahajan R, Ocfemia MCB, Su J, Xu F, Weinstock H. Sexually transmitted infections among US women and men: prevalence and incidence estimates, 2008. Sex Transm Dis. 2013;40(3): 187-93.

32. Schuster MA, Corona R, Elliott MN, Kanouse DE, Eastman KL, Zhou AJ, Klein DJ. Evaluation of talking parents, healthy teens, a new worksite based parenting programme to promote parent-adolescent communication about sexual health: randomised controlled trial. BMJ. 2008:337.

33. Statistics, N. C. f. H. Healthy People 2030. 2019. https://www.cdc.gov/nchs/ healthy_people/hp2030/hp2030.htm.

34. Tortolero SR, Markham CM, Peskin MF, Shegog R, Addy RC, Escobar-Chaves SL, Baumler ER. It's Your Game: Keep It Real: delaying sexual behavior with an effective middle school program. J Adolesc Health. 2010;46(2):169-79.

35. Underwood JM, Brener N, Thornton J, Harris WA, Bryan LN, Shanklin SL, Deputy N, Roberts AM, Queen B, Chyen D. Overview and methods for the youth risk behavior surveillance system-United States, 2019. MMWR Suppl. 2020;69(1):1

36. Villarruel AM, Loveland-Cherry CJ, Ronis DL. Testing the efficacy of a computer-based parent-adolescent sexual communication intervention for Latino parents. Fam Relat. 2010;59(5):533-43.

37. Walker TY, Elam-Evans LD, Yankey D, Markowitz LE, Williams CL, Fredua B, Singleton JA, Stokley S. National, regional, state, and selected local area vaccination coverage among adolescents aged 13-17 years-United States, 2018. Morb Mortal Wkly Rep. 2019;68(33):718.

38. Weinstock H, Berman S, Cates W. Sexually transmitted diseases among American youth: incidence and prevalence estimates, 2000. Perspect Sex Reprod Health. 2004;36(1):6-10.

39. Whitaker DJ, Miller KS. Parent-adolescent discussions about sex and condoms impact on peer influences of sexual risk behavior. J Adolesc Res. 2000;15(2):251-73.
40. Widman L, Evans R, Javidi H, Choukas-Bradley S. Assessment of parentbased interventions for adolescent sexual health: a systematic review and meta-analysis. JAMA Pediatr. 2019;173(9):866-77.

41. Xiao Z, Li X, Stanton B. Perceptions of parent-adolescent communication within families: it is a matter of perspective. Psychol Health Med. 2011;16(1): 53-65.

\section{Publisher's Note}

Springer Nature remains neutral with regard to jurisdictional claims in published maps and institutional affiliations.
Ready to submit your research? Choose BMC and benefit from:

- fast, convenient online submission

- thorough peer review by experienced researchers in your field

- rapid publication on acceptance

- support for research data, including large and complex data types

- gold Open Access which fosters wider collaboration and increased citations

- maximum visibility for your research: over $100 \mathrm{M}$ website views per year

At BMC, research is always in progress.

Learn more biomedcentral.com/submissions 